\title{
Central Portion of the Breast
}

National Cancer Institute

\section{Source}

National Cancer Institute. Central Portion of the Breast. NCI Thesaurus. Code C12300.

The part of the breast which is in the center. 